\title{
Socio-ARQUeOlogía de SAN BARTOLOMÉ DE los ChanÁ, REDUCCIÓN DE INDIOS
}

\author{
Ana Rocchietti ${ }^{1}$ y Nélida De Grandis ${ }^{2}$
}

\begin{abstract}
Resumen
San Bartolomé de los Chaná fue una reducción de indios fundada por Hernando Arias de Saavedra en 1616 como parte de su política territorial y como medio para dominar a las poblaciones autóctonas de vida semi-nómada en los ríos afluentes del Paraná entre Asunción y Buenos Aires. El siglo XVII fue crucial para los españoles para lograr asimilar a su imperio de la Cuenca del Plata. Este aporte tiene por finalidad ensayar algunas consideraciones epistemológicas sobre el registro arqueológico y su asociada documentación histórica.
\end{abstract}

Palabras clave: San Bartolomé de los Chaná, colonialismo español, reducciones de indios, Río de la Plata colonial, política española de Indias.

\begin{abstract}
San Bartolome de los Chaná was a reduction of Indians founded by Hernando Arias de Saavedra in 1616 as part of his regional policy and as a means to dominate the indigenous populations of semi-nomadic life in the tributaries of the Parana, between Asuncion and Buenos Aires. The seventeenth century was crucial for the Spaniards to achieve assimilate their empire Plata Basin. This contribution aims to rehearse some epistemological considerations on the archaeological record and its associated historical documentation.
\end{abstract}

Keywords: San Bartolome de los Chaná, Spanish Colonialism, Reductions of Indians, colonial Rio Plata, Spanish Indies Policy.

\section{Introducción}

Este trabajo está dedicado a presentar un análisis de carácter epistémico sobre la reducción de San Bartolomé de los Chaná, en relación con las características del colonialismo español durante el siglo XVII, en la Provincia de Santa Fe.

Colocar indios chaná y guaraní en policía y encomienda no se apartaba de los usos, costumbres y ley española en América. Por eso conviene vincular esta arqueología al carácter de las fundaciones de reducciones en la América española: tuvieron carácter a la vez, segregacionista, proteccionista e indicador del régimen de

\footnotetext{
${ }^{1}$ Centro de Estudios en Arqueología Histórica. Facultad de Humanidades y Artes, Posdoctorado. Secretaría de Posdoctorado. Universidad Nacional de Rosario. anaau2002@yahoo.com.ar

${ }^{2}$ Centro de Estudios en Arqueología Histórica. Facultad de Humanidades y Artes, Universidad Nacional de Rosario.nellyisis@hotmail.com
} 
castas del sistema social del que formaban parte. Lo más importante fue su razón de ser: extracción de trabajo indígena sea en forma de bienes o de servicios personales.

Siguiendo estas ideas, vamos a presentar los contextos de San Bartolomé cuya expresión como yacimiento es el paraje denominado La Boca del Arroyo Monje- y sus contenidos, problematizando críticamente la sociedad colonial que los originó y procurando delinear una socio-arqueología del proceso colonial a través del registro arqueológico. La cronología básica de que disponemos es la siguiente: 1. Inicio hacia 1616; se sabe por una carta al Rey por Hernandarias del 25 de mayo; 2. Empadronamiento de 50 personas; conviven dos caciques (uno chaná - timbú y otro guaraní) en 1621. El cacique chaná tenía a su cargo 18 personas y el guaraní 32 . Convivían y no se menciona mestizaje inter-étnico; 3. Vacancia en 1646 y aparecen los nombres de Francisco de Lencina y de Juan Paz: 4. En 1650 ocurre la visita de Garabito de León según la cual quedan sólo seis indios de tasa y Diego Tomás de Santuchos exige por sus derechos sobre esta tierra; 5. Visita de José de Herrera y Sotomayor en 1682; 6. En 1688 se presenta Tomás de Santuchos quien quizá hereda a Isabel Arias Montiel y Juan de Aguilera restando nueve indígenas. Por tanto, la secuencia de funcionamiento parece haber sido: 1. Instalación como reducción o pueblo de indios. 2. Visitas, 3. Despoblamiento. En el transcurso existen reclamos por derecho de posesión en el esquema de adjudicación sucesorio propio del sistema colonial español de la propiedad de tierras. Arqueológicamente se verifica su existencia en el paraje mencionado a través de los materiales españoles de la época, manufacturados y diseñados en la metrópoli y combinados con cultura material GoyaMalabrigo y guaraní. La encomienda en el paraje debió comenzar con el conquistador y poblador de Santa Fe La Vieja, don Luis del Barrio y debió segur con Pero (Pedro Gómez), en fecha incierta Dado que las reducciones de Hernandarias fueron una manera de sistematizar un proceso de consolidación territorial español, es de suponer que San Bartolomé duró poco tiempo como asiento de indios reducidos y que fue entregada a uno de estos dos encomenderos. Esto se deduce del hecho de que si bien era obligación de estos vecinos adoctrinar, al menos en la experiencia del Paraguay, encomenderos y reducciones fueron simultáneamente una necesidad y un conflicto, especialmente en el caso jesuita.

\section{Colonialismo}

El colonialismo en América tuvo dos etapas: una fue la de conquista de tierras y avance sobre las civilizaciones más desarrolladas del continente (aztecas, mayas e incas); la otra se desarrolló cuando se puso en pleno funcionamiento a las instituciones que España trasladó o diseñó para el vastísimo espacio americano. La primera fue salvaje y turbulenta, envuelta en destrucción y guerra; la segunda fue férrea en autoridad y dominio consumando una síntesis política original integrada por el Estado, la Iglesia y la aristocracia colonial absolutista y oligárquica. La extracción de materias primas -especialmente las mineras pero el Río de la Plata no las tenía- y el comercio sistematizó no solamente la producción de riqueza sino también la demarcación de las regiones con impronta europea. Durante los siglos XVI y XVII la 
unidad productiva fundamental fue la encomienda porque ella administraba y explotaba el trabajo indígena. En el Río de la Plata la riqueza estaba contenida en la vaquería y la encomienda estaba orientada a las actividades ganaderas.

Los órganos administrativos coloniales eran el Virrey, los capitanes generales y los gobernadores. El Virreinato del Perú (que incluía a los países actuales Perú, Ecuador, Colombia y Bolivia y -después de la primera Buenos Aires- a las comarcas rioplatenses hasta que en 1776 se convirtieran por orden de los Borbones ellas mismas en Virreinato) abarcó durante mucho tiempo al Paraguay a pesar de la distancia y de la tendencia autonomista que tuviera desde el principio esa región. Los gobernadores tenían, entre otras, funciones judiciales de primera instancia y, como los antiguos adelantados, la obligación de garantizar la presencia de la Corona en lo más remoto de sus jurisdicciones.

Hernando Arias de Saavedra (Hernandarias) fue el primer gobernador criollo en el Paraguay. Tuvo tres períodos de gobierno como teniente gobernador el 13 de julio de 1592 en conformidad con la provisión de la Audiencia del 20 de octubre de 1587. Gobernó en ese turno hasta 1593. Luego lo hizo entre 1597 y 1599, entre 1602 y 1609 (como Gobernador y Capitán General en Asunción, ratificado por la Corona por seis años, el 6 de noviembre de 1601) y entre 1615 y 1618 pero esta vez en Santa Fe (Maeder E y Gutierrez R. 1995). Se lo considera un hombre influyente y obedecido, incluso después de haber terminado sus funciones. Se trata de quien propusiera a la Corona dividir al Río de la Plata en dos gobernaciones: Guayrá y Buenos Aires. Ocurrió por Real Cédula del 16 de diciembre del 1617 reservándose la jurisdicción de la primera mientras era designado Diego de Góngora (1618 - 1623) para la segunda. Hernandarias es quien promueve la instalación de las reducciones franciscanas, entre ellas San Bartolomé de los Chaná. Santa Fe La Vieja (1573 - 1660), la ciudad más cercana a ella, quedó en esta última jurisdicción, en posición relativamente cercana a la salida al mar por Buenos Aires.

Las Audiencias fueron tribunales trasplantados por los Reyes Católicos que con el tiempo tuvieron cada vez más poder. Según Chaunú (1979), tuvieron más influencia que en España porque se transformaron en verdaderos Consejos de Estado que controlaban al virrey y eran símbolo de la justicia real omnipresente. La de Charcas, a la que habría de pertenecer Santa Fe La Vieja, fue creada en 1559 y en su jurisdicción estaba el territorio bastante insumiso del Paraguay y de las poblaciones del corredor paranaense.

La ideología fundamental afianzada en el proceso de la invasión española indicaba una tarea inexorable: cristianizar a los nativos sacándolos de su "estado natural" y aproximarlos a Dios por el camino de la civilización. No obstante, las reducciones venían a solucionar el problema de controlar a la población indígena, a inducirlas a aceptar la vida sedentaria y el entramado del comercio y vaquería para los cuales su trabajo debía ser estratégico. No fue sencillo lograr esta finalidad en las tierras bajas porque en ellas la población no tenía los estándares de organización y trabajo que requería el sistema extractivo español aún bajo las condiciones de la ruralidad bastante rústica que pretendían imponer. 
En 1508, dos bulas del Papa Julio II instituyeron el Patronato Regio sobre la iglesia de las Indias, lo cual significaba que el Vaticano abdicaba del control sobre el clero en el Nuevo Mundo a favor del Rey, contribuyendo a transformar a la Iglesia en una repartición administrativa en el Nuevo Mundo (López, 1988). Eso explica la atribución que tenía Hernandarias sobre el tema de las "reducciones en policía" que de todas maneras tenía que ser aprobada en España.

San Bartolomé y su paraje se encontraban en las tierras de encomienda de Pero Gómez, vecino de Santa Fe La Vieja (Areces y Tarragó, 1999; Calvo, 1999) a 80 leguas, río Paraná abajo. Los documentos relativos a la encomienda no han sido hallados. Se trató de una doctrina porque el sacerdote "visitaba" el lugar para cristianizar y permanecía un tiempo limitado en él. Sin embargo, parece que San Bartolomé tuvo iglesia de tapia, lo cual indicaría que hubo una tarea evangelizadora persistente. La presencia de un franciscano Fray Francisco Ibáñez - que no sabía la lengua- duró sólo dos meses. Luego siguió sin sacerdote alguno (Góngora, 1622).

\section{Breve historia de San Bartolomé}

San Bartolomé de los Chaná fue una humilde reducción de indios; no tuvo carácter formal ni de pueblo ni de poblado aunque uno de los cursos de agua cercano se llama justamente Río del pueblo; se fundó en el marco de una política de dominio colonial español basada en la conversión religiosa de población calificada como idólatra y estuvo subordinada a una encomienda, como era habitual en la época.

La reducción se encontraba en la intersección entre el río Coronda y el arroyo Monje, Provincia de Santa Fe, Argentina. El paraje, sobre costa firme, está frente a una sección del delta del Paraná, en el cual existen abundantes sitios arqueológicos prehispánicos pero ninguno colonial. Las fuentes históricas hablan de los antiguos pobladores como Chaná y la arqueología santafesina asigna a esta gente la expresión en la cerámica Goya-Malabrigo (Figura 1).

En la región había indios chaná por lo cual el nombre de la reducción es alegórico. La encomienda definía la responsabilidad de un propietario privado sobre la evangelización de indios, con carácter limitado temporalmente (una vida, dos vidas según cómo evolucionó la institución) y en calidad jurídica de vasallos. No obstante, inferimos, la habitación del paraje La Boca tuvo lugar primero como reducción, pasó a ser posesión de Luis del Barrio y luego de Pero Gómez en calidad de encomienda. Lo inferimos por la diferencia temporal entre la decisión de Hernandarias (1615/1616) y la fecha (1621) en que aparece el nombre de esta persona como encomendero siguiendo la cronología de Calvo (Calvo: 1999: 231-232).

Esta reducción reunió indígenas chaná -según algunas fuentes, prioritariamente pescadores- y guaraníes -quizá- trasladados desde Santa Fe la Vieja ubicada a casi un centenar de kilómetros hacia el norte $\mathrm{o}$, pobladores transitorios y esporádicos de La Boca. Los guaraníes eran gente corsaria de los ríos y cultivadores tropicales, famosos por ser comedores de carne humana. No puede decirse lo mismo de los chaná. Todos estaban a cargo de un sacerdote franciscano y el encomendero era un 
propietario ausente. No es seguro que el fraile permaneciera en esta pequeña misión un tiempo prolongado.

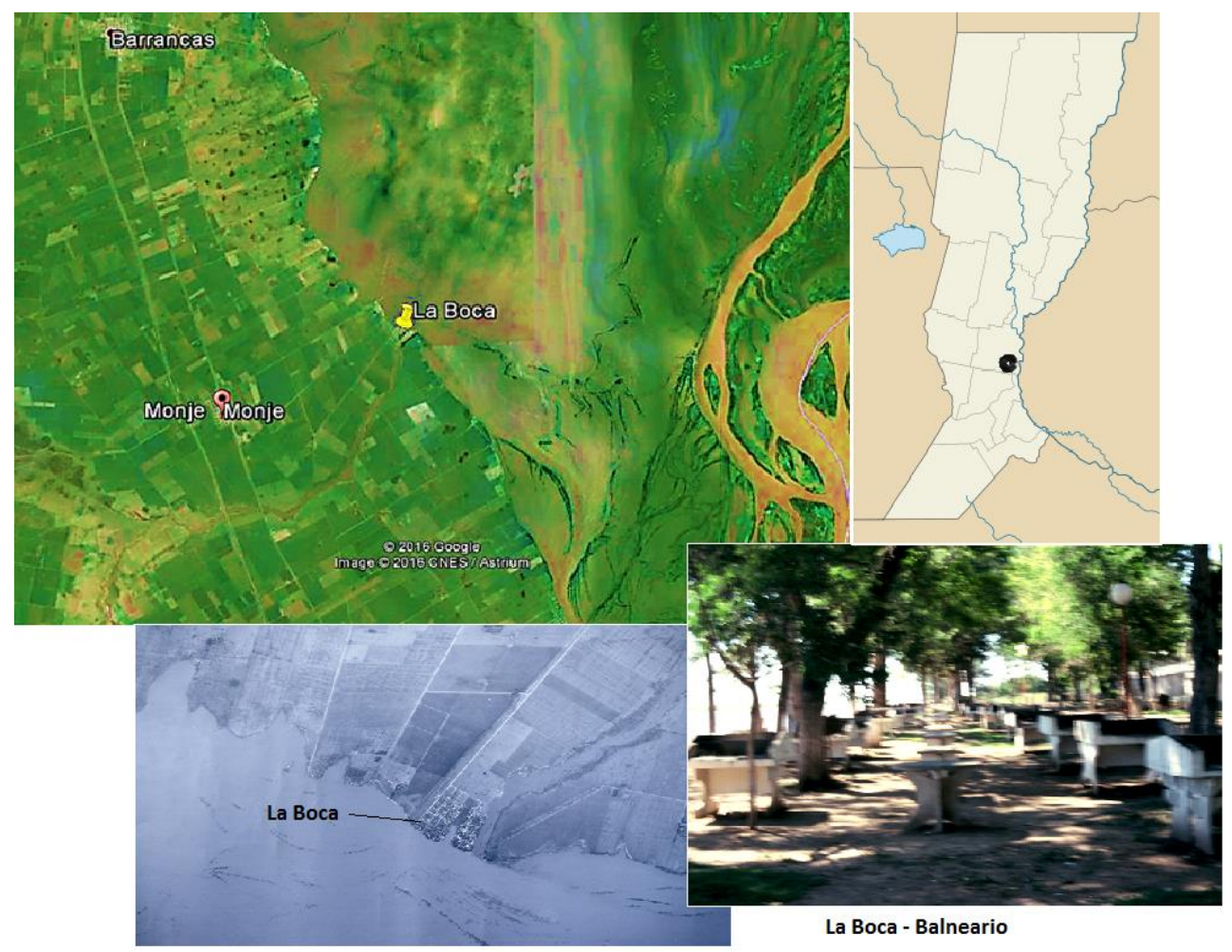

Figura 1. Ubicación San Bartolomé - La Boca

Los franciscanos fueron los primeros en formar reducciones en el Paraguay, bajo la acción de los sacerdotes Luis Bolaños y Alonso de San Buenaventura quienes arribaron en 1575 con el Adelantado Juan Ortiz de Zárate, aunque fueron precedidos por la presencia -frustrada- de los padres Bernardo Armenta y Alonso de Lebrón en 1538 (Abad Pérez,1992). Bolaños y Buenaventura se dirigieron al Guayrá para bautizar y catequizar indígenas. En 1580 se fundó el convento de la Asunción. La evangelización franciscana recibió el elogio de Hernandarias en una carta al Rey del 6 de mayo de 1607, destacando su procedimiento para hacer entrar en reducción a los caciques y sus indios (Córdoba 1937: 35).

En 1620 el sistema de encomiendas entró en crisis porque los indios se diezmaron en el litoral de los ríos por pestes (Areces et al 1999). Las enfermedades y el uso de trabajadores para transportar ganado despoblaron estos enclaves y las cosas evolucionaron hacia el trabajo asalariado aún con imperfecciones que hacían perdurar el régimen de servicio personal. Las encomiendas florecieron en el siglo XVII de esa gran región tanto como régimen de propiedad de la tierra como por explotación del trabajo de los indios consistente en guardar ganado, acarrear madera en balsas y servir (incluía cederlos en alquiler para levantar corrales) (Areces, 2002). 
La ideología franciscana tiene como elementos principales la pobreza y la predicación itinerante. Sus reglas fueron aprobadas por el Papa Inocencio III, con autorización para predicar, en 1209, aunque luego se completaron en 1221 y 1223. En 1217 la Orden se dividió en Provincias, cada una con su propio ministro, y al final del siglo XIII ya había en Europa, 1200 conventos; la Orden tenía carácter mendicante pero con el tiempo se tornarían monásticos y el trabajo manual así como las tareas más humildes las harían los criados seglares. Entre 1239 y 1245 se volvieron clérigos. Pero terminarían dividiéndose en los Rigoristas o Espirituales y los Moderados en torno a la problemática hermenéutica de la pobreza. Los primeros darían lugar a la Orden de los Menores, fieles a las prescripciones de San Francisco de Asis. Los espirituales tratarían de retornar al proyecto fundador y, con tal propósito, constituyeron la fuente de la acción de los misioneros descalzos, en América, dedicados a la atención de los pobres y de los enfermos (Córdoba, 1937).

Básicamente, la utopía franciscana tiene por sostén las siguientes ideas: el hombre se sitúa en la historia y en una naturaleza tensionada hacia el futuro; el acontecer humano se descifra desde una perspectiva de esperanza y su plenitud está en el futuro; el hombre asciende hacia Dios en forma gradual (Merino, 1982).

Probablemente estas intenciones y preceptos pudieron actualizarse en ocasión de la sociedad Chaná-Guaraní reducida.

\section{Arqueología de San Bartolomé}

La arqueología de San Bartolomé se encuentra en un paraje que lleva el nombre de La Boca. Éste es un topónimo muy habitual en las islas del Delta del Paraná ya que designa la confluencia de cursos de agua. En este caso, se trata del derrame del arroyo Monje en el caudaloso río Carcarañá, uno de los brazos del Paraná en esta latitud (S $32^{0} 19$ ' 59' 15 ' y W $60^{0} 52$ ' 30.01'). Ese arroyo sinuoso y de cauce estrecho atraviesa la pampa y desemboca frente al ambiente islero.

La imagen que tenemos de la reducción la dio el Informe de Góngora al Rey:

"En la jurisdicción de la dha ciudad de Santa fée 80 leguas de ella sobre el dho río del Paraná abajo hazia el puerto de Buenos Ayres está otra reducción nombrada San Bartolomé de los Chanaes de la cual cuando el dhogobernador pasó Río arriba a hazer la visita halló ningún yndio y a dos leguas de ella halló dos caciques con 18 indios sin mujeres ni hijos que andavan retirados por la enfermedad de viruelas y tabardillo que abia comenzado á darles de que dijeron que habían muerto algunos.

Mandó a estos dos caciques y á un español que saliesen a buscar los demás caciques e indios y les dijeron volviesen a la reducción y estuviesen en ella para cuando el dho gobernador viniese. También despachó en busca dellos desde la ciudad de Santa fée y cuando volvía navegando por dhorrío a hacer la visita destaredución tuvo noticiaestavan en una yslas y brazos del alguno de estos caciques é indios fue donde estavan y halló cantidad 
de ellos con sus mujeres e hijos en sus ranchos de toldos desteras que tenían hechos en tierras y en canoas y los recogió y trujo en su compañía hasta dha reducción donde halló otra cantidad que habían traido y recojió los dos caciques que embio en su busca. Estos indios dijeron que eran bautizados y algunos ynfieles andan vestidos algunos y desnudos de la misma calidad y costumbre que los otros indios tenían iglesia buena de tapia madera y paja y estos tenían en sus casas de palo y paja declararon que les trujeron de sus tierras que son en unas yslas sir cunvecinas al dicho asiento havia tres años por mandado de Hernando Arias de Saavedra y que no tenían cosa ninguna de comunidad y que alguno de ellos tenían algunos bueyes caballos y canoas.

Asi mismo declararon que habían tenido por su doctrinante á un religioso de San Francisco nombrado fray Francisco Ibáñez que no sabía su lengua por cuya causa habian muerto muchos y que ahora eran pocos y que se habian muerto de peste.

No tenían sacerdote no hornamento ni otra cosa para el servicio de la iglesia dijeron que el ornamento que tenían lo había llevado el padre fray de san Francisco de la ciudad de Santa fée y ansi estaban sin sacerdote y sin ornamento y todos los que morían eran sin conficion y que por que tenían ya hecha y casas y buen agua montes y leña pescaderas y tierra para pescar y sembrar estaban contentos empadronáronse y hubo 133 yndios 86 yndias 102 muchachos habiendo llegado al puerto de Buenos Aires con mucho cuidado y brevedad hizo con el guardian de San Francisco que embiase y embió a esa reduccion un religioso sacerdote nacido en la tierra que sabe muy bien la lengua de los indios." (En Cervera, 1982: 385 - 386).

Lo que hace de esta acumulación de materiales españoles e indígenas la expresión de la que fuera la reducción es la combinación de sus bienes: abundantes mayólicas españolas, vidrios, cuentas venecianas y cerámicas Goya - Malabrigo, Guaraní e instrumentos líticos.

El sitio se localiza en una sección de la barranca alta cortada por un paleocauce del arroyo Monje, con un perfil albardonado que exhibe en la costa una pila formada por un horizonte húmico que apoya sobre un limo-loéssico impregnado con abundante carbonato. Ésta es visible cuando el río está bajo y actualmente sostenida por una defensa de cemento que no existía cuando lo excavamos. Los primeros 0.15 $\mathrm{m}$ del perfil están alterados por la actividad de balneario que tiene lugar en el sitio: se debe a los asadores y mesas que dan confort a los turistas y acampantes de fin de semana. En el extremo norte del predio hay baños con duchas y una instalación que alguna vez fue un kiosco. Sobre la superficie en la que antes existió San Bartolomé se encuentran viviendas, un residencial y comercios, varias calles sobre las que circulan vehículos y una torre de agua. En las partes en las que hay tránsito o erosión aflora el material arqueológico aunque los procesos que desatan ambos han empobrecido casi completamente este registro. Tomamos conocimiento de él en 1990 y 
procedimos a su estudio en forma casi continua porque lo dedicamos a escuela de entrenamiento de campo para alumnos de arqueología. El sector que resultó más íntegro se ubica sobre la margen izquierda del arroyo, casi sobre la boca o desembocadura; le dimos el nombre de área crítica para distinguirla del resto del yacimiento ya que su estratigrafía era mucho más segura. Se excavó por decapage y rindió materiales hasta los 0.60 metros. En la playa se registraron los materiales mediante unidades por sectores de concentración de materiales superficiales.

El resultado fue una distribución homogénea, con forma de nube ya que los ítems se dispersaban de modo parejo en el sedimento húmico, sin describir concentraciones ni restos de fogón, predominando las cerámicas indígenas altamente fragmentadas. Es el único sitio en todo el polígono comprendido entre las latitudes $\mathrm{S} 32^{0}$

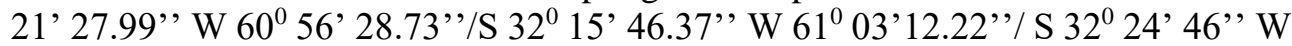
$60^{\circ} 40^{\prime} 53.25^{\prime}$ '/ S $32^{0} 25^{\prime} 09.92$ ', W $60^{\circ} 45^{\prime} 19.51^{\prime \prime}$ ' que abarca la terraza fluvial y las islas que exhibe la combinación hispano-indígena. Si vivieron en la reducción unas trescientas personas no debieron ser albergadas en el albardón de La Boca porque hubiera implicado casi hacinamiento. Si los indios vivían en sus parajes isleños hasta allí no llegaron los bienes españoles por lo cual éstos tendrían que ser considerados como una pertenencia personal del sacerdote que no circularon más allá de su hábitat. A él pueden ser asignadas las mayólicas de Talavera, Columbia Liso, Panamá Polícromo e Ichtucknee, una tacha y las botellas de vidrio. Las cuentas debe haberlas llevado esta persona o, quizá, un capataz pero no necesariamente para usarlas; es más probable que las entregara a los indios o que fueran cuentas de rosario, es decir, de un elemento para cristianizar.

Los fragmentos de cerámicas indígenas forman dos grupos: uno corresponde a cuencos con y sin decoración, de cocción imperfecta, y adornados -en algunos casos- por pequeñas esculturas que representan animales (Goya-Malabrigo) o con agujeros de suspensión; otro son recipientes con decoración pintada de los clásicos tipos guaraníes, unguiculados y corrugados

El conjunto se completa con instrumentos líticos: bolas de boleadora, punta de proyectil y raspadores pequeños. Los consideramos estratigráficamente coetáneos (Rocchietti y De Grandis, 1996, 2007, 2009, 2011, Rocchietti et al, 1994, 1997, 2007).

¿Quiénes eran estos indígenas? Si la reducción concentró población islera vecina, eran Chaná, posiblemente asignables a Guaycurúes-chaqueños, de vida adaptada a ese paisaje de agua, pescadores, cazadores y cultivadores de abatí, dispersos en los albardones de los cursos que se tienden entre el Carcarañá y el Paraná.

Los guaraníes manifiestan su indudable presencia. Sus cerámicas son inconfundibles. ¿Qué hacían ahí? Los Chaná y el resto de las poblaciones del litoral tenían frecuentes intercambios de bienes con ellos pero era gente bravía y guerrera, con canibalismo ritual. Quizá no pueda ser afirmado con seguridad que pudo existir una convivencia inter-étnica normal a menos que se verificara la alianza española-guaraní que había dado tanto resultado en el Paraguay y que estuvieran asentados en la reducción para colaborar en lograr la mansedumbre Chaná.

Loponte et al (2011) revisando la arqueología guaraní del delta a través de la dispersión de unos escasos sitios (Arroyo Largo, Arroyo Fredes, Arroyo Malo, 
Arenal Central, El Arbolito, Martín García), algunos trabajados por ellos y otros conocidos desde el siglo XX, afirman que no se conocen hasta el momento sitios guaraníes en la margen continental del Paraná ni en el Delta Superior y costa uruguaya, que es posible que hubiera circulación de sus bienes (al menos, en la costa rioplatense hasta el Atlántico) y recuerdan que los cronistas señalaron la relación conflictiva que tenían con los grupos locales ya sea por rivalidad o por competencia sobre los recursos. También señalan que el ecosistema de las islas era muy adecuado para los guaraníes debido al bosque y a sus buenos suelos. En el mismo volumen, Andrade examina la cuestión de atribuir identidad étnica al registro arqueológico indicando la necesidad de que la disciplina preste atención a la cuestión de la etnicidad, la cual ha recibido interés teórico en la Antropología contemporánea, pero advirtiendo sobre la violencia interpretativa que esto conlleva.

Quizá habría que problematizar qué tipo de acumulación arqueológica indica el término sitio guaraní. Porque ella puede comprender un conjunto en el que la totalidad de los ítems responde a esa connotación o, por el contrario, a la dominancia de su cerámica. En las islas de nuestro polígono no existen ni lo uno ni lo otro tanto en islas como en terraza pero sí abundantes yacimientos Goya-Malabrigo. No obstante, los tiestos guaraníes están entre los Goya-Malabrigo en La Boca. O los trajo el sacerdote como parte de su ajuar (no sabemos desde donde vino el fraile, quizá desde Asunción o desde Santa Fe La Vieja aunque quien lo sucedió provino desde Buenos Aires) o los intercambiaron los Chaná o, directamente, vivieron todos juntos como parte de la estrategia reduccional española. Esta situación de los materiales en este paraje es lo que llamamos San Bartolomé reduccional (Figura 2).

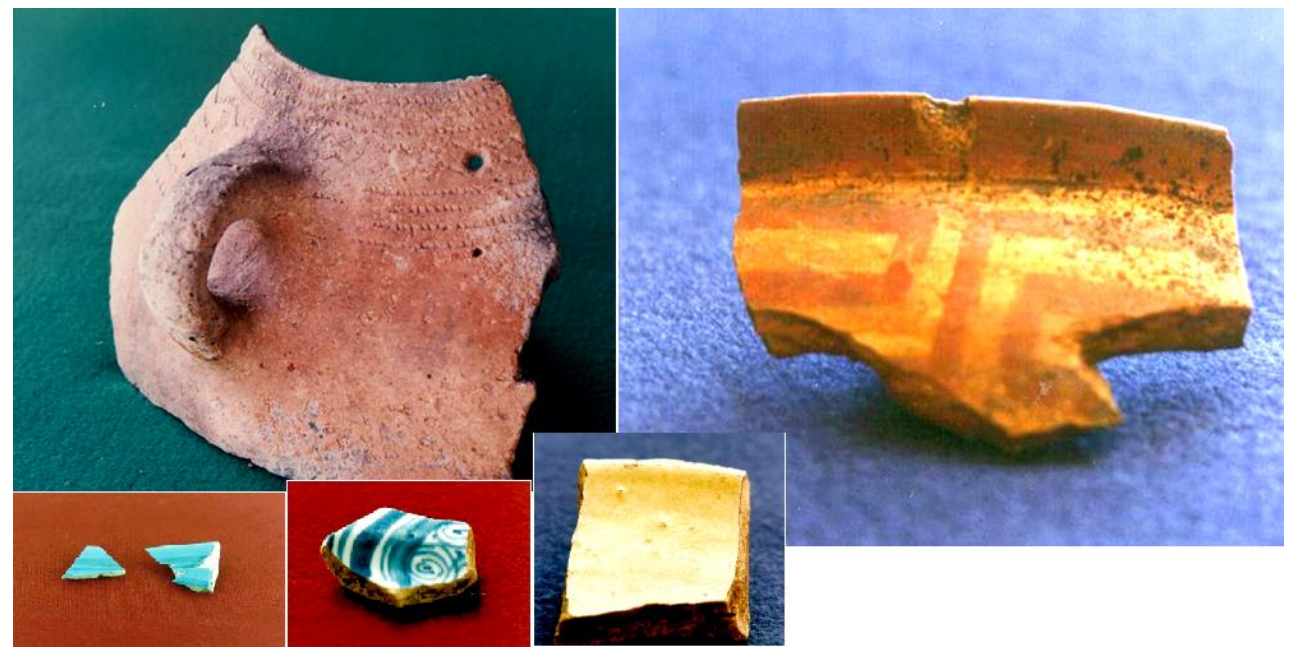

Figura 2. Convivencia de cerámicas en San Bartolomé - La Boca

Resta la cuestión de la asignación étnica a las cerámicas Goya-Malabrigo como Chaná. Es también un tema pleno de dificultad. Goya Malabrigo parece coincidir por unos dos mil años -desde el comienzo de la era cristiana- con un área de 
población litoral de raigambre chaqueña, ceramistas de un arte modelado impresionista. Puede ser violencia interpretativa pero también es cierto que el poder efectuar la correlación cerámicas arqueológicas- etnias históricas quizá sea una dimensión específica de la Arqueología Histórica.

\section{Arqueología e Historia}

Los españoles tomaron posesión de América a través de las ciudades, la más de las veces meros asentamientos precarios y con funciones urbanas limitadas. La arqueología se ha concentrado en ellas (las más notables, Panamá Viejo, Santa Cruz de la Sierra y Santa Fe La Vieja). También lo ha hecho en las misiones jesuíticas dada la envergadura del proyecto evangelizador y político que las creó. Las misiones franciscanas en el Paraná argentino fueron Baradero (Provincia de Buenos Aires), San José de Bagual (Provincia de Buenos Aires) y la del cacique Tubíchaminí (Provincia de Buenos Aires), Santa Lucía de los Astor (Provincia de Corrientes), Nuestra Señora de la Limpia Concepción de Itatí (Provincia de Corrientes) y en la Provincia de Santa Fe -que nos ocupa- San Lorenzo de los Mocoretás, San Miguel de los Calchines y nuestra San Bartolomé. Varadero (o Baradero) fue localizada y excavada mientras que las demás todavía no han sido ubicadas.

Entre 2500 y 1800 años atrás estas poblaciones antiguas se volvieron ceramistas y alrededor de la era cristiana podrían haber empezado a fabricar canoas para viajar entre los ríos y riachos. Hacia 800 o 1000 DC alcanzaron el dominio de toda la llanura aluvial. A medida que se instalaban las condiciones climáticamente húmedas, los pobladores pasaban a depender, cada vez más, de los ecosistemas acuáticos. Es probable que el conocimiento de la tecnología cerámica (que llegaron a dominar como expertos, si se juzga por la importancia de la fracción cerámica y la calidad expresiva de su arte modelado en los registros) lo obtuvieran a partir de su comunicación (o procedencia originaria) con los habitantes de la Amazonía (inconmensurable país del corazón sudamericano) alrededor del 400 AC (Cf. Rodríguez, 1992).

Sin embargo, la caracterización económica está en revisión ya que al sobredimensionar la orientación social hacia los recursos acuáticos dejó de estimar la agricultura. Nuevas investigaciones aportan nuevos detalles sobre este género de vida en las islas (Cf. Bonomo et al, 2008, Bonomo et al, 2011a, Politis et al, 2011b). Para los tiempos de la penetración de las expediciones españolas en el Río de la Plata lo más probable es que estas poblaciones ya tuvieran sus chacras y ellas empezaran a ser su base económica.

Nosotros pensamos que los registros de nuestra área de estudio pueden ser observados en términos del concepto de formación arqueológica, homóloga -pero no reductible- al de formación geológica, para describir un tipo sistemático de contenido de depósito en lugares de distribución de cultura material arqueológica (Rocchietti, 2002). Clasificamos el componente Chaná en el sitio de la reducción como perteneciente a la Formación Goya-Malabrigo (no en sentido cultural sino como tipo de depósito) usando el nombre que ha perdurado en la tradición académica de la región (Rocchietti et al, 1999: 490 - 491). La Boca del Monje -un sitio histórico reduccional 
de indios isleros- en cambio, incorporó a su contenido ergológico materiales guaraní y españoles por lo que la sistematizamos como una formación o acumulación específica a la que damos su nombre y cuyo contenido describimos como asociación de materiales españoles, Goya Malabrigo y Guaraníes.

Loponte (2008), Loponte y Acosta (2008) y Cocco (2010) señalan, en general, que uno de los defectos del estado del conocimiento arqueológico sobre la región es la poca precisión que existe en la bibliografía precedente sobre el contenido de los depósitos del Holoceno reciente o tardío. Por nuestro conocimiento de la esa geografía arqueológica, estamos en condiciones de afirmar que los sitios arqueológicos revisten tres categorías: seguros, re-depósitos e históricos.

Hay sitios de tipo seguro, esto es con representación amplia de tecnología, dieta y otros rasgos de terreno que inclinan a pensar que, aparte de las transformaciones propias de un ambiente de alta energía hídrica, corresponden a contextos propios de asentamientos humanos; por el contrario, los registros probables o improbables suelen consistir en distribuciones cerámicas en las que los fragmentos tienen alto rodamiento y pueden clasificarse como re-depósitos. El grado de entrampamiento en el sedimento contribuye a dar mayor valor contextual a las posiciones seguras. La Boca -o San Bartolomé- es un típico yacimiento o sitio con documentación asociada (Rocchietti, 2002, 2011); no sólo tiene valor contextual sino que es informado por datos que provienen de precisiones administrativas españolas. Pero por el momento es un sitio único en nuestro polígono de investigación y su ausencia de redundancia no puede ser adscripta a una formación arqueológica o depósito estratigráfico típicamente expandido en la región. No obstante reviste el carácter de histórico por su documentación asociada.

En la Provincia de Buenos Aires, existe un importante registro de la reducción franciscana de Santiago de Baradero, vigente entre 1615 y 1756 (Tapia, 2002, 2014; Tapia et al 2009; Tapia et al, 2015; Kozameh et al, 2015). Posee una amplia documentación histórica asociada a un cementerio indígena, con mejor y más contexto que La Boca y con demostración de las condiciones de privación en que vivía la población indígena y el mismo sacerdote puesto que los restos humanos analizados sugieren desnutrición y descalcificación.

La formación arqueológica típica -redundante- en esta parte del Delta pertenece a esa formación que designamos Goya Malabrigo. Se trata de depósitos que parecen haber tenido larga duración ya que pueden remontarse a los comienzos de la era cristiana o, quizá, anteriormente ofreciendo testimonio - en esta latitud- del asentamiento de poblaciones influidas por el ambiente de río y por un estilo de desarrollo económico derivado de condiciones climáticas subtropicales en bosques de litoral. La continuidad entre las sociedades de esta asignación arqueológica y la reducida en San Bartolomé puede aceptarse con alta probabilidad.

Las condiciones iníciales, es decir, aquellas en las que un registro arqueológico adquiere sus características como formación arqueológica son las siguientes:

1. Ambiente de alta energía hídrica que proviene del Paraná y su cuenca que produce dos efectos: uno son las acumulaciones sedimentarias a partir de bancales arenosos en áreas de inundación lagunares (bañados, maciegas) y 
en albardones de crecimiento lateral y otro las geoformas erosionadas por corrientes de agua de alta velocidad.

2. Hidro-período muy variante pero generalmente de crecientes entre septiembre y marzo.

3. Terrenos planos o convexos cubiertos por abundante vegetación herbácea y arbórea.

4. Estratigrafías confusas ocasionadas aportes laterales bajo flujos de agua lentos o de erosión predominantemente hídrica subordinados al régimen de crecientes-bajantes del río Paraná.

5. Escasa visibilidad del material arqueológico con excepción en las bajantes, lo que hace que los sitios se identifiquen por los perfiles de las barrancas o por superficies de pisoteo del ganado vacuno llevado para engorde a las islas.

6. Empobrecimiento de los depósitos arqueológicos por migración de materiales hacia otros puntos del río debido al efecto de arrastre del agua, creando acumulaciones de material arqueológico que no se corresponden con antiguos asentamientos.

7. Procesos mecánicos de movimiento de los materiales sea por deslizamiento gravitatorio (vectores verticales de deslizamiento), sea por flujos de vaivén por oleaje (vectores horizontales).

Estas condiciones han sido observadas por nosotros en numerosos sitios de isla. En La Boca han tenido menos incidencia por la altura de la costa sobre el pelo del agua tanto respecto al río Coronda como al arroyo Monje. En este emplazamiento lo que ha destruido el registro es la erosión hídrica lateral.

La Formación Goya Malabrigo responde a procesos de asentamiento humano en el Corredor Paranaense (con eje norte - sur predominante); habitat cuya característica principal es haber sido atractor y fijador de un poblamiento autocontenido (por su carácter insular y por los recursos que ofrece el medio). Los indios isleños fueron habitantes de un vasto humedal, con albardones costeros en un ambiente cuyo evento-acontecimiento principal era y es la inundación Los albardones son, pues, geoformas hidrogeológicas singulares y le dan especificidad a la región. Un verdadero sistema de tierras. No parece haber habido aquí diferencias notables entre la población ribereña (o costera, sobre la cota de barrancas) y las isleras. Si fueron canoeros nada pudo haberlos detenido para recorrer un amplio radio geográfico.

Todo sitio de hábitat humano es una posición en el espacio en el que la Naturaleza está mediada socialmente, constituyendo un ecosistema "humanizado". Los albardones deltaicos, en particular revisten singularidad topográfica, biótica y sistémica tanto como producto del modelado del ambiente fluvial como por la elección que de ellos hicieran los isleños (los antiguos y los modernos). Esta relación puede ser abarcada bajo el concepto de tierra o de ecología del terreno (Sánchez, 2009).

Los acontecimientos ocurridos en La Boca -probable asentamiento tradicional Goya-Malabrigo en el comienzo, asignación de la tierra en encomienda, traslado de indígenas al paraje, instalación del misionero, arribo de guaraníes, epidemia, regreso a las islas- dejaron una distribución pobre en restos de bienes pero indicadora 
de la potencia del sistema colonial porque cuando se los censa es para poner en marcha la tributación de los indios de tasa (varones entre 18 y 50 años) así como de la contundencia de las relaciones inter-étnicas.

\section{La seguridad del contexto}

El registro arqueo-histórico -por la documentación que tiene asociada- de San Bartolomé -La Boca de Monje aporta algunas dimensiones epistemológicas que deseamos plantear. ¿Qué efectos tiene el contexto en la seguridad del modelo?

En primer lugar examinaremos los modelos posibles que pueden sustentarse en él. Estimamos que son dos a los cuales se podría postular un tercero. .

El modelo 1 postula un San Bartolomé reduccional monocomponente triétnico (español/chaná/ guaraní). Este modelo se sustenta en las cerámicas.

El modelo 2 presenta un San Bartolomé sólo bicomponente con cerámicas guaraníes agregadas pero no necesariamente convivientes con los otros materiales, posiblemente diacrónico o circunstancial e, incluso, aportado por un ajuar personal, no local.

El modelo 1 permitiría construirse sobre lo que se sabe de la historia regional sobre la base de la hegemonía de las cerámicas. El modelo 2 pone en primer plano la estructura interna en el depósito, básicamente de dominancia cerámica. El resto de los sitios arqueológicos del polígono no rindieron materiales guaraníes; están concentrados en La Boca lo cual señalaría que ellos fueron llevados allí intencionalmente para la reducción, cuestión que se adivina en el inventario de caciques que, dice la documentación, fue bi-étnico.

Pero también podría formularse un modelo aleatorio (3) determinado por una presencia esporádica para hacer intercambios de bienes. En este esquema pueden asimilarse también los instrumentos líticos que podrían explicarse por una diacronía estratigráfica tanto como por una presencia adherida de modo estocástico (por ejemplo, una partida de gente venida transitoriamente desde la llanura y ajena al ambiente islero. Pero se adjudica históricamente a los chaná el uso de bolas de boleadora por lo cual su presencia en el ajuar económico puede considerarse, asimismo, completamente local.

La seguridad del modelo tiene que reposar necesariamente en la posibilidad de encontrar coherencia en los kits tecno-etnológicos. Nosotros suponemos que, en este caso, todo forma un contexto único y que el modelo reduccional se ajusta bien a una cotidianeidad de carácter doméstico, rural y colonial.

\section{Consideraciones finales}

Es difícil encontrar una correlación segura entre documentos y contexto arqueológico y entre los componentes heterogéneos del depósito de La Boca. La más contundente prueba consiste en el registro de los materiales europeos en una geografía tan marginal en la época. El colonialismo español tuvo dos expresiones hasta cierto punto contradictorias: ciudades/fortalezas vs aislados hábitats de pesquería y 
vaquería. Es muy posible que, en este último caso, las penurias fueran terribles sobre todo porque se rompían los nexos más profundos de los indios con su entorno de agua y su vida tradicional.

También habría que encontrar la regla de referencia respecto a la palabra contexto. Puede hacerse una contextualización situacional, otro relevante y, por fin, determinante (Schuster, 1999). La diferencia depende de los factores que han actuado sobre el registro arqueológico y esto habrá de depender del marco teórico que aliente la investigación o el análisis. En el primer caso ellos se configuran, en cada circunstancia, de acuerdo con el medio y el conjunto total de condiciones tanto de la sociedad extinta como del registro arqueológico; en el segundo importan los factores o causalidad más importante o central en el proceso y, por último, las variables realmente causales o productoras de efectos en uno y otro aspecto en consideración. ¿Cuál es el realismo del contexto y cuál es la realidad de un contexto seguro?

Si el contexto es una percepción o una decisión del investigador entonces su existencia dependerá de su utilidad. Pero si corresponde al mundo objetivo, entonces el contexto habrá de ser algo por demarcar, describir y explicar. A pesar de lo que parece, se trata de un dilema no fácil de resolver porque se oscila entre la apariencia de la experiencia y la convicción (o no) de que "algo" está allí. La relación con la documentación o con la historiografía no es menos complicada pero ellas ofrecen la sensación de que iluminan al registro y lo hacen más "humano". La seguridad de un contexto arqueológico depende mucho más del ambiente en el que se inserta, sea en un sitio o en una escala territorial.

Areces (2002) enumera los problemas que inducen los documentos: denominación confusa de las agrupaciones indígenas, datos demográficos no confiables aun cuando el número de pueblos y parcialidades parece haber sido muy significativo, alcance impreciso del alcance territorial que tenían éstos, muchos nombres mencionados por los cronistas pero no en los Expedientes Civiles ni en las Escrituras Públicas que obran en el Museo etnográfico de Santa Fe; finalmente, la información 'provista por los indígenas proviene de los mediadores y lenguaraces.

La dominancia ceramista del trabajo indígena en su hábitat personal, familiar o comunitario es llamativa en toda la región. La mayoría de los sitios consisten en acumulaciones de tiestos lo cual podría indicar el valor de estos recipientes en su desarrollo económico de las harinas (de pescado, de abatí o maíz) o de los destilados (chichas). Si acostumbraron vivir en sus canoas o arrojaron los desechos directamente al agua, entonces tenemos un registro empobrecido por los hábitos y no por la hidrodinámica.

En San Bartolomé - La Boca, por el contrario, el registro se enriquece por nuevos bienes que acompañan la entrada europea y las necesidades religiosas y de confort que ella supone. La cultura material -aún en contextos sociales en los que ha predominado la tradición- se caracteriza por ciclos de innovación e inercia: éste sería el caso de ambas etnias indígenas pero en una etapa histórica en la que los extranjeros trataron de incidir y transformar a esas sociedades por convencimiento o por trato brutal. Es posible que en los tiestos encontráramos los esfuerzos por sostener la reproducción social frente al colonialismo español. 


\section{Notas}

${ }^{1}$ Ministerio de Innovación y Cultura de la Provincia de Santa Fe. Resolución 739, 10 - 12 - 2013.

\section{Referencias bibliográficas}

ABAD PÉREZ, A. 1992 Los franciscanos en América. MAPFRE. Madrid.

ANDRADE LIMA, T. 2011 O problema da atribucao de identidades étnicas a registros arqueológicos. En D. Loponte y A. Acosta (editores) Arqueología Tupíguaraní. Instituto Nacional de Antropología. Buenos Aires: 7 - 22.

ARECES, N. 2002 Los expedientes civiles del Departamento de Estudios Etnográficos y Coloniales de Santa Fe. Una lectura etnohistórica de Santa Fe La Vieja. Cuadernos de Historia, Serie Ec. y Soc., N 5, CIFFyH-UNC, Córdoba 2002: 191-200.

ARECES, N. y G. TARRAGÓ 1999 Encomiendas y vecinos: estrategias y trasgresiones. En N. R. Areces (compiladora) Poder y Sociedad. Santa Fe La Vieja, 1573 1660. Escuela de Historia. Universidad Nacional de Rosario. Manuel Suárez Editor y Prohistoria. Rosario: 61 - 87.

BONOMO, M., I. CAPDEPONT Y A. MATARRESE 2008 Alcances y limitaciones en el estudio de colecciones. Los materiales arqueológicos del Delta del río Paraná depositados en el Museo de La Plata". Revista de Arqueología Sudamericana 5(1): 68-101. Universidad del Cauca, Colombia.

BONOMO, M, F. J. ACEITUNO, G. POLITIS Y M. L. POCHETTINO 2011a PreHispanic horticulture in the Paraná Delta (Argentina): archaeological and historical evidence. World Archaeology Vol. 43(4): 554-575.

BONOMO, M.; G. POLITIS Y C. GIONOTTI 2011b Montículos, jerarquía social y horticultura en las sociedades indígenas del delta del río Paraná (Argentina). Latin American Antiquity 22(3): 297-333.

CERVERA, M. 1982 Historia de la ciudad y Provincia de Santa Fe. Contribución a la Historia de la República Argentina. 1573 - 1853. Tomo III. Universidad Nacional del Litoral. Santa Fe de la Veracruz.

COCCO, G. 2010 Nuevos aportes al estudio de los procesos de Formación del Registro Arqueológico en la Provincia de Santa Fe. En M. Berón, L. Lima, M. Bonomo, C. Montalvo, C. Aranda y M. Carrera Azpitarte, Mamul Mapu: pasado y presente desde la arqueología pampeana. Editorial del Espinillo. Ayacucho: 47-58. 
CALVO, L. M. 1999 Pobladores españoles de Santa Fe la Vieja (1573-1660). Academia Nacional de la Historia. Buenos Aires.

CHAUNÚ, P. 1979 Historia da América Latina. DIFEL. Río de Janeiro.

GONGORA, D de. 1622 Relación de lo hecho por el Gobernador D. Diego de Góngora en la Visita General que hizo en la Provincia del Río de la Plata. 2 de marzo. Audiencia de Charcas, Legajo27. MEJBA C 14. Buenos Aires.

KOZAMEH, L.; A. TAPIA; M. LOPEZ y N. TESTA 2015 Restos óseos humanos fragmentados del cementerio indígena de Baradero: Alcances y limitaciones de su estudio bioarqueológico. Comechingonia [online]. vol.19, n.1:131-154 http://www.scielo.org.ar/scielo.php?script=sci_arttext\&pid=S185100272015000100007\&lng=es\&nrm=iso>

LOPEZ, L. R. 1988 Historia da América Latina. Mercado Aberto. Porto Alegre.

LOPONTE, D. 2008 Arqueología del Humedal del Paraná Inferior (Bajíos ribereños meridionales). Instituto Nacional de Antropología y Pensamiento Latinoamericano. Buenos Aires.

LOPONTE, D. Y A. ACOSTA 2008 El registro arqueológico del tramo final de la Cuenca del Plata. En D. Loponte y A. Acosta (comp.) Entre la tierra y el agua. Arqueología de humedales del este de Sudamérica. Asociación Amigos del Instituto Nacional de Antropología y Pensamiento Latinoamericano. Buenos Aires.

LOPONTE, D., A. ACOSTA, I. CAPPAROLLI y M. PÉREZ 2011 La arqueología guaraní en el extremos meridional de la cuenca del Plata. En D. Loponte y A. Acosta (editores) Arqueología Tupíguaraní. Instituto Nacional de Antropología. Buenos Aires: $111-154$.

MAEDER, E.J.A. s.d. Nómina de gobernantes civiles y eclesiásticos de la Argentina durante la época española (1500 - 1810). Instituto de Historia. Facultad de Humanidades. Universidad Nacional del Nordeste. Resistencia.

MAEDER, E Y GUTIERREZ R. 1995. Atlas Histórico del Nordeste Argentino. Resistencia. Instituto de Investigaciones Geohistóricas. CONICET. Fundanord y Universidad del Nordeste.

MERINO A. 1982 Humanismo Franciscano. Editorial Cristiandad. Madrid.

ROCCHIETTI, A. M. 2000 La Boca del Monje: un sitio reduccional para indios isleros (siglo XVII). En VIII Reunión Científica de Arqueología Brasileira. 12 al 15 
de septiembre de 1995. Centro de Cultura y Ciencias de la Pontificia Universidad Católica de Río Grande de Porto Alegre. Grande do Sul. Brasil. Actas. CD.

2002 Formaciones arqueológicas con documentos históricos histórica asociada: la investigación social del registro arqueológico. En Arqueología Histórica Argentina. Actas del $1^{\circ}$ Congreso Nacional de Arqueología Histórica. Ediciones Corregidor. Buenos Aires. Argentina.

2011 Arqueología histórica como campo de la teoría social. En Temas y problemas de la Arqueología Histórica. Tomo I. Programa de Arqueología Histórica y Estudios Pluridisciplinarios. Departamento de Ciencias Sociales. Universidad Nacional de Luján. Pp. 19-33.

ROCCHIETTI, A.M. Y N. DE GRANDIS 1996 La Boca del Monje: un sitio reduccional para indios isleros (siglo XVII). Anais da VIII Reunião Cientifica PUCRS. Colecao Arqueologia. Porto Alegre. EDIPURCS, nº 1, vol. 2: 327-342.

2007 Economía islera en el Holoceno Tardío: un modelo exploratorio para las distribuciones arqueológicas de la latitud Monje - Gaboto. Museo Antonio Serrano. Paraná. CD.

2009 Problemas de arqueología colonial: examen del registro de San Bartolomé de los Chaná. Simposio de Arqueología Colonial. Cayastá. Santa Fe. 13 y 14 de agosto. Departamento de Arqueología. Escuela de Antropología. Facultad de Humanidades y Artes. Universidad Nacional de Rosario.

2011 Problemas de arqueología colonial: San Bartolomé de los Chaná. Reducción y encomienda de Pedro Gómez, vecino de Santa Fe la Vieja en el río Coronda. Actas del Simposio de Arqueología Colonial. Cayastá. Santa Fe. Anuario de Arqueología Año 3 Número 3. Departamento de Arqueología. Escuela de Antropología. Facultad de Humanidades y Artes. Universidad Nacional de Rosario.

ROCCHIETTI, A. M., N. DE GRANDIS Y M. S. CARBALLO 1994 Arqueología del área Gaboto - Monje. En Actas y Memorias del XI Congreso Nacional de Arqueología Argentina. San Rafael. Mendoza (segunda parte). Revista del Museo de Historia natural de San Rafael, tomo XIV, No 14: 264-266.

ROCCHIETTI, A. M., N. DE GRANDIS, B. VICIOSO Y L. MARTÍNEZ 1997 La Boca del Arroyo Monje. Los indios isleros y la invasión europea en el siglo XVI. En Primeras Jornadas de la Cuenca del Plata y Segundas de Etnolingüística. Escuela de Antropología. Facultad de Humanidades y Artes. Universidad Nacional Rosario. Tomo IV, Arqueología.

ROCCHIETTI, A. M., B. VICIOSO, N. DE GRANDIS, M. VALENTINI 2007 Arqueología de los indios isleros. En R. Bolmaro y A. Pifferetti (eds) Primer Congreso Nacional de Arqueometría. Escuela de Antropología (Facultad de Humanidades y Artes) y Escuela de Agrimensura (Facultad de Ingeniería). Universidad Nacional de Rosario. Rosario. 
RODRÍGUEZ, J. A. 2001 Nordeste Prehispánico. En E. E. Berberián y A. Nielsen (editores) Historia Argentina Prehispánica. Tomo II. Editorial Brujas. Córdoba: 693 -736 .

SÁNCHEZ, R. 2009 Ordenamiento Territorial. Bases y estrategia metodológica para la ordenación ecológica y ambiental de tierras. Ed. Orientación. Buenos Aires.

SCHUSTER, F. 1999 Los laberintos de la contextualización en ciencia. En G.Althabe y F. G.Schuster Antropología del Presente. Edicial. Buenos Aires. 23 - 42.

TAPIA, A. 2002. Indicadores biológicos y culturales de la conquista en el Delta del Paraná (siglos XVI y XVII). Relaciones de la Sociedad de Antropología XXVII: 357-374.

TAPIA, A., C. LANDA, H. DE ROSA, \& E. MONTANARI 2009 Artefactos metálicos de las inhumaciones del "Cementerio Indígena" de Baradero. En O. Palacios, C. Vázquez, T. Palacios y E. Cabanillas (Eds.) Arqueometría Latinoamericana. Comisión Nacional de Energía Atómica, Buenos Aires: pp. 263-269.

TAPIA, A. H. 2014 Cambio cultural y persistencia de las identidades nativas en la sociedad colonial de Baradero (siglos XVII y XVIII). Revista del Centro de Arqueología Histórica,

TAPIA, A. E., NÉSPOLO y V. NOYA. 2015 Santiago del Baradero. Origen y evolución de un pueblo de indios. Editorial Pangea. Buenos Aires.

Recibido: 12 de abril 2016.

Aceptado 27 de septiembre 2016. 